\title{
Clozapine-induced intestinal obstruction - a critical examination of four cases
}

C Seller, MB ChB, MMed (Psych)

L Koen, MB ChB, MMed (Psych)

D J H Niehaus, MB ChB, MMed (Psych), DMed

Ngaphakathi Workgroup, Department of Psychiatry, Stellenbosch University

Clozapine is an atypical antipsychotic drug indicated for the management of severely ill patients with schizophrenia who fail to respond adequately to standard antipsychotic treatment. It has demonstrated superior efficacy in treating both the positive and negative symptoms in treatment-refractory cases.' It also has the added benefit of causing minimal extrapyramidal sideeffects, producing no tardive dyskinesia and having little effect on prolactin levels. ${ }^{2}$

Although clozapine has a number of side-effects (Table I) clinical focus falls mainly on the serious adverse effects of agranulocytosis (0.38 - 1\%) and seizures (1 - 6\%). ${ }^{2}$ However, constipation is a much more common side-effect occurring in $14-60 \%$ of patients, ${ }^{3,4}$ with a total of 5 fatalities (all males) having been described in the literature. ${ }^{4-8}$ In terms of the 5 fatalities significant variations in dosage (400-750 mg/d) and duration of treatment with clozapine (36 days - 6 years) were

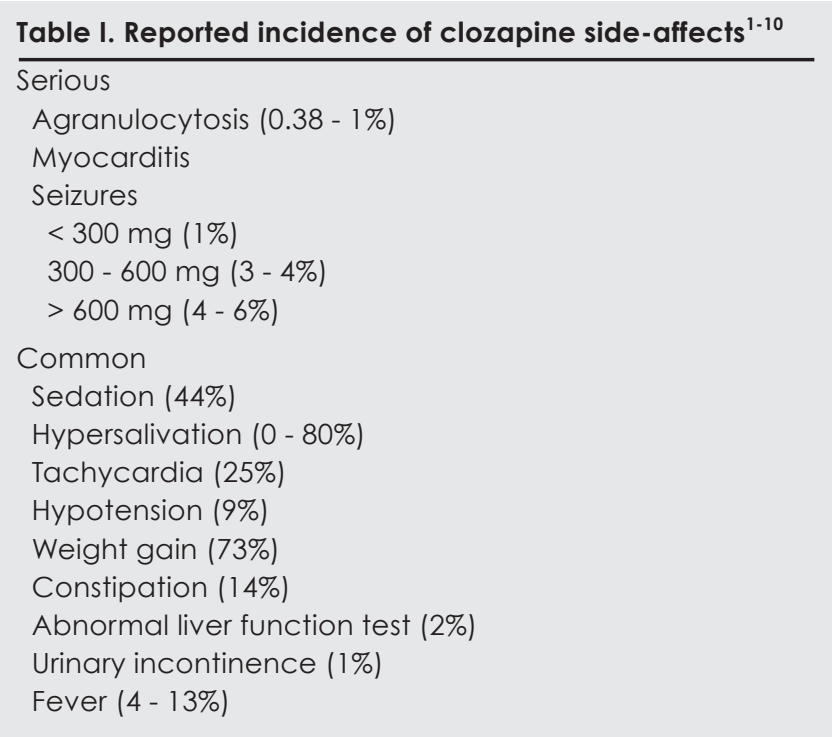

described. Of these, 2 patients died of aspiration pneumonia (bowel obstruction with faecal vomitus), 2 died secondary to large-bowel necrosis and ischaemia due to faecal impaction, and 1 due to colon perforation with faeculant peritonitis. Furthermore, a number of publications have reported on cases of serious clozapine-induced constipation. In Australia, of 15 cases reported ${ }^{9} 4$ concerned faecal impaction, 2 subacute bowel obstruction and 1 rectal prolapse. A French report ${ }^{10}$ of 30 cases requiring treatment documented 3 cases of intestinal obstruction requiring surgery.

Lentegeur State Psychiatric Facility is 1 of only 3 dedicated psychiatric facilities serving a population of 6 million in the Western Cape region of South Africa. When clinical notes of male inpatients on clozapine (from November 2002 to April 2004) were reviewed retrospectively, 3 deaths and 1 patient needing treatment in intensive care were identified.

\section{Cases}

\section{Case 1}

A 35-year-old man with a diagnosis of schizophrenia of 6 years' duration and mild intellectual impairment presented with acute abdominal symptoms. He had been started on clozapine 12 days before the onset of his symptoms because of non-response on other antipsychotics. The dosage had been increased by $25 \mathrm{mg}$ every 3 days; at onset of symptoms he was on 150 $\mathrm{mg} / \mathrm{d}$. He was also on chlorpromazine, which was being cross-tapered and had been stopped 2 days before symptoms started. There was no previous medical history of note. He presented with acute onset of abdominal cramps, abdominal distension, dyspnoea and drowsiness. On examination he was found to have respiratory distress with wheezing, and a distended and tender abdomen with increased bowel sounds. Special investigations revealed faecal impaction labdominal radiograph) and aspiration pneumonia (chest radiograph). His condition deteriorated and he required intubation and ventilation for 9 days before recovering. He was readmitted 
to Lentegeur 3 weeks later and clozapine was reinitiated. Special care was given to an even slower increase in dosage, and attention was paid to proper diet and stool patterns. His psychiatric condition stabilised and he was discharged without lasting sequelae.

\section{Case 2}

A 43-year-old man had been diagnosed with disorganised schizophrenia more than 20 years previously and had been on treatment with clozapine for more than 10 years. He had been institutionalised for the past 3 years because of ongoing symptomatology, and in the 4 months before his death the clozapine dosage had been gradually increased from $400 \mathrm{mg}$ to $700 \mathrm{mg} / \mathrm{d}$. The patient was not receiving any concomitant treatment and there was no medical history of note. He presented with acute onset of food refusal, and a distended, tender abdomen. At the medical facility he was found to have bowel obstruction secondary to faecal impaction and was taken to theatre for a laparotomy, but he had a cardiac arrest during surgery. A postmortem revealed a markedly distended colon filled with large amounts of liquid faeces and air. The entire colon showed ischaemic change that was almost necrotic in some areas.

\section{Case 3}

A 23-year-old man had been diagnosed with schizophrenia 4 years previously and had moderate intellectual impairment (IQ 50). He had been on several combinations of treatment before clozapine, e.g. haloperidol $(10 \mathrm{mg} / \mathrm{d})$ and carbamazepine $(600 \mathrm{mg} / \mathrm{d})$, trifluoperazine $(10 \mathrm{mg} / \mathrm{d})$ and sodium valproate (1 $200 \mathrm{mg} / \mathrm{d}$ ). Clozapine was initiated and increased to $400 \mathrm{mg}$ in just 1 week. There was no previous medical history. Three weeks before his death he presented with food refusal and self-induced vomiting, against a backdrop of severe paranoid delusions and extreme thought disorder. A full organic work-up was done but only showed a mildly elevated white cell count and an iron deficiency. After a 3-day history of severe abdominal cramps, constipation and 1 episode of vomiting he was medically referred and found to have peritonitis with rebound and increased bowel sounds. The patient died 3 days later with a clinical diagnosis of bowel perforation. The abdominal radiograph showed faecal impaction. A postmortem was requested, but not done.

\section{Case 4}

A 56-year-old man had been diagnosed with schizophrenia for more than 30 years and had been treated with clozapine (300 - 400 mg/d) for 15 years. He was known to have hypertension (on enalapril $5 \mathrm{mg} / \mathrm{d}$ ) and clozapine-induced seizures (on phenytoin $300 \mathrm{mg} / \mathrm{d}$ ). He also had a longstanding history of chronic constipation for which he had received 2 full organic work-ups (1 by a physician). In the ward he had numerous physical complaints, often of constipation and diarrhoea. He was also markedly thought-disordered with delusions regarding 'black poison' influencing the digestion of his food. He was referred to the tertiary gastro-intestinal clinic because of concerns regarding his chronic abdominal

Table II. Summary of cases

\begin{tabular}{|c|c|c|c|c|}
\hline & Case 1 & Case 2 & Case 3 & Case 4 \\
\hline Age (yrs) & 35 & 43 & 23 & 56 \\
\hline Diagnosis (DSM-IV) & $\begin{array}{l}\text { Schizophrenia (6 years) } \\
\text { Mild MR }\end{array}$ & $\begin{array}{l}\text { Schizophrenia } \\
\text { (>20 years) }\end{array}$ & $\begin{array}{l}\text { Schizophrenia (5 years) } \\
\text { Moderate MR (IQ: } 50 \text { ) }\end{array}$ & Schizophrenia (36 years) \\
\hline Medical history & Nil & Nil & Nil & $\begin{array}{l}\text { Hypertension } \\
\text { Clozapine-induced } \\
\text { seizures }\end{array}$ \\
\hline Onset of side-effects & $\begin{array}{l}\text { 1/7: drowsy, dysp- } \\
\text { noea, abdominal } \\
\text { distension }\end{array}$ & $\begin{array}{l}\text { Acute onset: food refusal, } \\
\text { tender distended } \\
\text { abdomen }\end{array}$ & $\begin{array}{l}\text { 3/52: vomiting, food } \\
\text { refusal } \\
1 / 52 \text { after clozapine } \\
\text { peritonitis }\end{array}$ & $\begin{array}{l}\text { > } 2 \text { years chronic consti- } \\
\text { pation: } \\
\text { LOW, hiccoughs }\end{array}$ \\
\hline $\begin{array}{l}\text { Special investigation } \\
\text { findings }\end{array}$ & $\begin{array}{l}\text { AXR: faecal impaction } \\
\text { CXR: aspiration } \\
\text { pneumonia }\end{array}$ & $\begin{array}{l}\text { AXR: bowel obstruction } \\
\text { due to faecal } \\
\text { impaction } \\
\text { †, PM }\end{array}$ & $\begin{array}{l}\text { AXR: faecal impac- } \\
\text { tion } \\
\dagger-\text { perforation }\end{array}$ & $\begin{array}{l}\text { AXR: severe faecal } \\
\text { load. } \\
\text { † before barium meal } \\
\text { ?? CA }\end{array}$ \\
\hline $\begin{array}{l}\text { Treatment before } \\
\text { onset of side-effects }\end{array}$ & $\begin{array}{l}\text { 12/7: clozapine } \\
\text { Chlorpromazine cross- } \\
\text { taper }\end{array}$ & $\begin{array}{l}\text { Clozapine }>10 \text { yrs } \\
4 / 12: \uparrow 400-700 \mathrm{mg}\end{array}$ & $\begin{array}{l}\text { Several combinations } \\
\text { Clozapine } 0-400 \mathrm{mg} \\
\text { in } 1 / 52\end{array}$ & $\begin{array}{l}\text { Clozapine (1989) } \\
\text { Phenytoin (2003) } \\
\text { Enalapril }\end{array}$ \\
\hline
\end{tabular}


complaints, weight loss and hiccoughs. On referral he had no acute abdominal findings. An abdominal radiograph showed large quantities of faecal material and evacuation was attempted. He died before the barium meal could be performed. A postmortem was not performed, but the question of underlying malignancy was raised.

See Table II for a summary of case data.

\section{Discussion}

Constipation is a common side-effect of a large proportion of psychotropic drugs. The assumption is made that constipation is an anticholinergic side-effect due to gastric motor dysfunction and delayed gastric emptying. ${ }^{5}$ In the case of clozapine a contributing factor could be longstanding use of high dosages of other antipsychotic treatment with the accompanying decreased bowel motility, before switching to clozapine.

There seem to be two mechanisms whereby clozapine-induced constipation can be fatal. The first is bowel obstruction leading to distension and necrosis of the bowel, followed by acute abdomen and sepsis. The second is bowel obstruction with inhalation of faeculant material/vomitus. The literature review revealed 5 deaths -2 as a result of aspiration pneumonia and 3 as a result of acute abdomen and sepsis. ${ }^{4-8}$ This correlates with the findings of our study where 3 patients died as a result of bowel obstruction and 1 as a result of aspiration pneumonia.

Another common element is that the diagnosis is often difficult or delayed. There seem to be two possible explanations for this, the first being altered pain sensitivity, and the second being difficulty in expressing pain. The phenomenon of a possible syndrome of pain insensitivity in patients with schizophrenia has been described. "' A confounding factor could be the use of neuroleptic and anticonvulsant medication, both with sedative and pain-modulating effects. Patients with schizophrenia may also find it difficult to express their pain. ${ }^{12}$ This is especially apparent in patients with marked negative symptoms and severe thought disorder (difficulty in organising thoughts so as to complain or express pain). If a patient is paranoid, especially towards the staff, conveying the symptoms could be problematic. An additional component of difficulty in expressing pain could be the presence of intellectual impairment. Complaints might not be articulated because of a lack of adequate vocabulary, or requests might not be heard or valued by staff.

It would seem therefore that a number of risk factors are involved in the development of clozapine-induced constipation, especially in chronically ill patients who are institutionalised. These patients are often on high dosages of antipsychotic treatment, especially clozapine. ${ }^{4}$ There is also the possibility of concomitant treatment, with further anticholinergic effects (anticonvulsants, tricyclic antidepressants, and chlorpromazine). Many patients also remain symptomatic, with severe thought disorder, disorganised behaviour, and paranoid delusions. ${ }^{8}$ Furthermore, institutionalised patients are less active, and have poor diet (lack of fibre) and low fluid intake. Risk factors in our case studies are listed in Table III.

These cases and the ones described in the literature emphasise the risks involved if clozapine-associated constipation is unrecognised or left untreated. Clozapine constipation protocols such as the Atascadero State Hospital protocol could be useful in preventing fatalities. ${ }^{4}$ Before initiating clozapine a flat abdominal radiograph (to exclude faecal load) and physical and rectal examination must be done. After initiating clozapine a daily flow sheet (dietary and bowel habits), referral to a dietician, regular exercise, adequate oral fluid and highfibre diet must be implemented as standard practice. Regular bulk-forming laxatives or stool softeners are prescribed when necessary. Furthermore a slow clozapine titration schedule is advised, with increases of no more than $25 \mathrm{mg} /$ day to a maximum of $100 \mathrm{mg} /$ week.

In conclusion, it is clear that clozapine-induced constipation is common and that it can be fatal if left untreated or

\section{Table III. List of risk factors found in case studies}

Case 1
Disorganised type
Low IQ
Combination of clozapine and chlorpromazine
(++ anticholinergic effects)
Case 2
Disorganised type
Low baseline functioning
Chronic clozapine use, high dosages
Chronically institutionalised
Case 3
Disorganised type
Low IQ
Three weeks of vomiting (possible faecal impaction/
psychosis)
Very rapid increase in clozapine (0 - 400 mg in 1 week)
Case 4
Chronic illness (> 30 years)
Chronic clozapine
Concomitant anticonvulsant
Possible underlying malignancy


unrecognised. In the South African state psychiatric facilities there is a high rate of use of clozapine, probably because of limited availability of other novel antipsychotic medication. There should be an increased awareness among all mental health care providers regarding the risk of constipation in institutionalised patients and the sequelae of this, and also a low threshold for investigating and treating clozapine-induced constipation.

\section{References}

1. Kane J, Honigfeld G, Singer J, et al. Clozapine for the treatment-resistan schizophrenic: a double-blind comparison with chlorpromazine. Arch Gen Psychiatry 1988; 45: 1789-1796.

2. Miller DD. Review and management of clozapine side effects. J Clin Psychiatry 2000; 61: suppl 8, 14-17.
3. Sandoz Laboratories. Clozapine Product Information. East Hanover, NJ, 1991.

4. Hayes G, Gibler B. Clozapine-induced constipation. Am J Psychiatry 1995; 2: 298

5. Drew L, Herdson P. Clozapine and constipation: a serious issue. Aust N Z Psychiatry 1997; 31: 149-150.

6. Shammi CM, Remington G. Clozapine induced necrotizing colitis. J Clin Psychopharmacol 1997; 17: 230-232.

7. Freudenreich $O$, Goff DC. Colon perforation and peritonitis associated with clozapine. J Clin Psychiatry 2000; 61: 950-951

8. Levin TT, Barrett J, Mendelowitz A. Death from clozapine-induced constipation. Psychosomatics 2002; 43: 71-73

9. Mathew T, Desmond P, Isaacs D, ef al. Constipation: it can be severe with clozapine. Australian Adverse Drug Reactions Bulletin 1999; 18: 12-15.

10. Theret L, Germaine ML, Burde A. Current aspects of the use of clozapine in the Chalons-sur-Marne Psychiatric Hospital: intestinal occlusion with clozapine (French). Ann Med Psychol (Paris) 1995; 153: 474-477.

1 1. Dworkin RH. Pain insensitivity in schizophrenia: a neglected phenomenon and some implications. Schizophr Bull 1994; 20: 235-248.

12. Bickerstaff LK, Harns SC, Leggett RS, et al. Pain insensitivity in schizophrenic patients. A surgical dilemma. Arch Surg 1988; 123: 49-51. 